\title{
Mudde, CAS y Rovira Kaltwasser, CRistóbal (2019): POPULISMO: UNA BREVE INTRODUCCIÓN ALIANZA EDITORIAL
}

\section{Marina Jareño Romera ${ }^{1}$}

Este Libro es un pequeño manual para la explicación del fenómeno del populismo; trata de aclarar cuáles son (o han sido) sus formas de actuación y manifestación allí donde se ha dado. El abordaje conceptual que los autores realizan se enmarca dentro de la filosofía política, por tanto, aunque refiere algunos de los hechos sociales con los que el fenómeno se relaciona, no se trata de un análisis de carácter empírico o aplicado.

El término populismo (como nos indican los autores) está lejos de tener un significado riguroso y unívoco, de ahí que dediquen el primer capítulo a esclarecer cuál puede ser su definición más precisa. Parten de lo que denominan un «enfoque

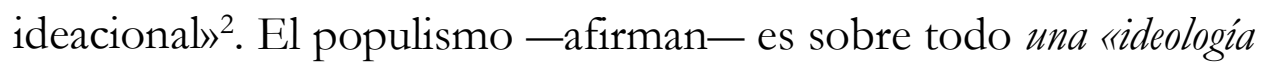
delgada» que divide a la sociedad en dos campos homogéneos y antagónicos, el «pueblo puro» frente la «élite corrupta», y la política debe ser la expresión de

1 Grado de Sociología. Universidad de Barcelona

2 Este es uno de los diversos enfoques existentes sobre el populismo pudiendo ser otras propuestas también relevantes: el enfoque de la «agencia popular», el de Laclau, el socioeconómico, el estrategico-político o el folclórico, entre otros. 
la voluntad general del pueblo. Es decir, el populismo, se entiende como una ideología de morfología restringida (mínima y esquemática) que, por definición, requiere de otras ideologías más robustas, complejas y estables, en función de las cuales se configuran los diversos tipos de populismo posible. Estas son llamadas «ideología huésped».

Partiendo de esta conceptualización esencialista, el texto nos señala que cualquier forma de populismo real que se articule se confronta a dos visiones de la sociedad: una elitista y la otra pluralista. En esencia, los autores están afirmando que cualquier forma de populismo contiene la negación de una sociedad elitista (organizada bajo la concentración de poder en manos de una clase o élite) pero también de una sociedad pluralista (si ésta se ha hecho efectiva mediante una distribución de poder entre los distintos grupos organizados que compiten con el mismo fin).

Entre los conceptos centrales que articulan la concepción del populismo se destacan tres:

- «El pueblo» que, dada la poca especificidad del término, permite la inclusión y la adaptación al colectivo amplio e indeterminado que representa "toda la sociedad".

- «La élite» que se identifica con el grupo que concentra el poder político, económico y/o mediático, y que (según estipula la "delgada" ideología populista) puede actuar de forma corrupta en contra del pueblo y de su voluntad. En este sentido, la clasificación y distinción sobre quién es la élite se apoya más en un criterio moral que situacional. 
- Y la «voluntad del pueblo» (que alude al concepto de JeanJacques Rousseau de volonté générale) que es la que une al pueblo en una única comunidad para legislar a favor de los intereses que son comunes al pueblo; para reforzar o fortalecer tales intereses; para promocionar la construcción de instituciones que actúan en consonancia con tal voluntad. Son estos intereses comunes del pueblo los que se ven reforzados por el populismo cuando éste promete el desarrollo de instituciones que van asegurar la promoción de la supuesta voluntad popular. En esto radica la verdadera fuerza del populismo, que se presenta como "democratizadora" incluso aunque ello conlleve negar o poner en peligro la voluntad de minorías.

En el segundo capítulo el fenómeno populista se contextualiza en las sociedades modernas de tres principales zonas: Norteamérica, Latinoamérica y Europa.

En Norteamérica, el populismo se remonta a finales del siglo XIX y es caracterizado por la existencia de un liderazgo central y una débil organización. En la primera ola populista de este contexto histórico su base es moral, geográfica y ocupacional. Surge en las transiciones sociales y económicas de principios de siglo, y se articula en base a los principios del progresismo agrario. Una segunda ola populista emerge de nuevo en Estados Unidos coincidiendo con los inicios de la Guerra Fría y es articulada por la corriente anticomunista de ese período. Finalmente, vuelve a resurgir en la primera etapa de este siglo XXI concretándose en las reivindicaciones populistas de derechas. 
En el caso del populismo latinoamericano este está presente de manera recurrente en la historia, probablemente debido a la gran desigualdad económica, resultado del balance final del período colonial, que incrusta -en su carácter y en su estructura social- una forma corrupta de oligarquía y el desarrollo de una débil política democrática. En este caso se dan tres olas populistas principales: la iniciada durante la gran depresión hasta los años 60 con la «crisis de incorporación social» del "pueblo", que coincide con las demandas de derechos políticos y sociales e ideologías como el socialismo y el comunismo. Una segunda ola de impronta neoliberal mucho más corta, que aparece a principio de los 90's. Y finalmente, la ola iniciada con el ascenso al poder de Hugo Chávez en Venezuela, con tendencias socialistas y de izquierda radical, y articulando como centro de su discurso (de nuevo) la cuestión de la desigualdad social.

En Europa, el populismo no empezó a emerger de forma relevante hasta a principios de los años 90 , momento en que avanzó de forma distinta en la Europa Occidental — conectada al nativismo o el posfascismo - y en la Oriental — conectada a un liderazgo personalista, anti-elitista y anticomunista. Los autores dictaminan que el populismo en Europa ha tendido a ser, en general, una corriente de derechas, pero la Crisis (y la Gran Recesión asociada) ha desencadenado recientes prácticas de populismo de izquierdas que son nuevas en esta parte del planeta.

Esta revisión de la historia del populismo se completa haciendo referencia (aunque de manera muy esquemática) a otras regiones, como Australia y Oriente Próximo. 
En el tercer capítulo, se resaltan las distintas formas de concreción populista -que pueden funcionar de manera combinada- subrayando básicamente tres. El liderazgo personalista, entendido como aquel individuo que basa su campaña en su atractivo personal para establecer una conexión con el votante. De esta forma, el líder pasa a ser el que confiere identidad al movimiento político, por lo que no requiere de una organización política robusta para llevar a cabo su estrategia, sino que se sirve de una organización débilmente construida, como simple «vehículo electoral personalista», y bajo su control absoluto. En la mayoría de los casos, lo que se articula es un «partido flash ${ }^{3}$ ».

La segunda forma populista está centrada en un movimiento social, que se desarrolla de forma ascendente y continuada por individuos, colectivos y organizaciones políticas que buscan un objetivo o ideal común de forma no institucionalizada. Esta forma de movilización no es un ejemplo del fenómeno populista que tienda a sostenerse en el tiempo porque nace con una debilidad intrínseca: carece de la fortaleza que otorga un líder fuerte.

Finalmente, el populismo puede estar promocionado por determinados partidos políticos, para los que el líder no actuaría como «núcleo vehiculador de la movilización», como en el primer caso apuntado. Estos partidos remarcan, como su principal potencial, la capacidad para dar voz a las cuestiones sociales relevantes no atendidas por los partidos tradicionales. En general,

\footnotetext{
${ }^{3}$ Entendidos como partidos inestables en el tiempo caracterizados por una alta volatilidad. En este caso su existencia va directamente ligada a la presencia del líder.
} 
estos partidos tienen una estructura organizativa fuerte y robusta y se sirven, además, de organizaciones auxiliares para producir y promocionar sus discursos.

La combinación de estos tres modos de movilización populista conforma lo que los autores llaman un «modelo dinámico», entendido como un proceso mutante con el que (como efecto de la combinación de los diferentes tipos de movilización) el populismo adquiere una ideología más clara y estructurada.

El libro explora, a continuación, los rasgos específicos de la figura del líder populista, el cual puede presentar formas muy heterogéneas, aunque en todos los casos adquiere en papel de representación del pueblo o vox populit, y es un «hombre fuerte»y carismático. Los tipos de líderes populistas son presentados a partir de la asociación de tres criterios o categorías: género, profesión y etnicidad. En cuestión de género, cuando se da el caso de "una" líder, ésta construye su figura de outsider denunciado precisamente que la mayoría de los pertenecientes a la élite política son hombres. Por añadidura, refuerza su figura mostrándose como una «buena» mujer, madre y esposa, creando así un vínculo de autenticidad con «el pueblo». Por lo que respecta al criterio profesional, destaca el líder empresario. Aunque, a priori, podría pertenecer al establishment, su posición es presentada como resultado del esfuerzo y la honestidad, únicos

4 Hecho que es potenciado con la construcción conceptual de la «elite» y el «pueblo» y el enfrentamiento que hacen de estos, así como la conexión que crea el líder para presentarse a sí mismo como perteneciente de este segundo. 
garantes de su éxito en los negocios. Su acceso a la política es, por tanto, totalmente desinteresado. Finalmente, encontramos los líderes por rasgos étnicos, cuya variación está en función de si son propios de populismos de extrema derecha europeos (la elite y el pueblo se divide entre «nativos»y «extranjeros») o etnopopulismos americanos (élite y pueblo divididos por la moralidad y etnicidad), es decir, conformados por el contexto político y social de cada región.

A grandes rasgos, lo que hacen los líderes populistas es situarse cómo outsiders, señalando que son nuevos en política, que su compromiso político no está basado en el interés y que su objetivo es trasladar la voz del pueblo. No obstante, como señalan los autores, muchos de ellos suelen tener antecedentes en política, acostumbran a tener conexiones con la élite y su estatus socioeconómico tiende a ser alto.

En el quinto capítulo, se intenta llegar a un consenso sobre las consecuencias que puede desencadenar el ascenso del populismo para el equilibrio de los sistemas democráticos. Las democracias liberales, según la ideología populista, limitan al demos y restringen su voluntad. Es en este sentido que el populismo se considera iliberal y, por el hecho de serlo, acaba por soslayar los derechos de la minoría. No obstante, su ascenso se basa en su capacidad para (en cierto sentido) politizar aspectos que previamente no habían sido atendidos o no se habían tenido en cuenta, así como en su capacidad para integrar sectores de la sociedad previamente excluidos. 
En consecuencia, los autores apuntan dos procesos inversos que puede seguir el populismo en relación a la democracia: o democratización, o des-democratización. Estos dos, pueden pasar por cuatro estadios de desarrollo político distintos: autoritarismo pleno, autoritarismo competitivo, democracia electoral, democracia liberal. Siguiendo esta tesis, se concluye que el populismo puede inducir a una democratización en regímenes autoritarios, pero también puede disminuir la calidad democrática en las democracias liberales.

Por último, se señalan algunos de los motivos del éxito del populismo. Es vital, para explicar su ascenso, el tipo de oferta y de demanda que realiza la política populista y su conexión con el contexto socioeconómico y sociopolítico en el que se teje. Su ascenso, por lo general, tiene lugar cuando en el contexto social se percibe que no hay respuesta a las demandas sociales, o en contextos con corrupción sistémica. Además, cabe prestar atención al papel que desempeñan los medios de comunicación y en qué medida actúan como mecanismos de activación de ideologías populistas. En general, los medios de comunicación promueven el populismo, no por razones de confabulación, sino porque su cobertura informativa se centra esencialmente en identificar temas vendibles para ganar audiencia. En este sentido, también las redes sociales pueden contribuir, en este momento, a fomentar una movilización populista de las clases medias en la medida en que son un mecanismo de comunicación y conexión eficaz entre sus miembros, con el que pueden expandir, además, de manera rápida sentimientos de anti-establishment. 
Para los autores, el populismo no es anti-democrático per se sino iliberal, aspecto que nos presenta la cuestión como algo mucho más complejo y difícil de resolver. La receta que dan los autores a esta situación es, en primer lugar, evitar o reducir la demanda de políticas populistas combatiendo la corrupción y, en caso de haberla, hacerle frente sancionando aquellos involucrados con el fin de reducir su repetición sistemática y remarcar el no sometimiento a la élite cuando ésta se comporta de manera corrupta. En segundo lugar, cabe evitar la sensación de no representación y no responsabilidad políticas, esclareciendo en cada momento el motivo de la acción concreta que realizan los que gobiernan. También es posible llevar a cabo una tercera medida, y esta es previa al surgimiento de los populismos, mediante la aplicación de estrategias activas de orientación a las masas que promuevan su educación cívica.

En retrospectiva, el breve manual permite construir una visión transversal del populismo partiendo del mero concepto y pasando por sus múltiples formas, tanto a nivel teórico como fenomenológico, señalando algunas de las consecuencias adversas que este puede tejer. Asimismo, afronta temáticas complejas y poco tratadas en el debate público, como es la cuestión de la relación entre populismo y democracia.

Este es un texto breve que puede servir como un buen punto de partida para rastrear las muchas preguntas a las que los autores no responden, pero sí suscitan: ¿En qué circunstancias cabría esperar una presión y una función política que destaparan con rapidez los casos de corrupción? ¿Cuáles son las estrategias 
de activación de las masas? ¿Cuáles son las que emplean los populismos y cuáles son las que pueden incrementar la crítica y la autonomía de la población? ¿Cómo redirigir en otra dirección la actuación mediática mercantilista que favorece el discurso populista? ¿Cuál es la línea que separa el discurso populista de la propaganda política ejercida en democracias, y en qué momento esta línea se rebasa?, etc. 